\section{KEY POINTS}

- Asian Development Bank (ADB) produced a stocktake of the environmental dimensions of the Sustainable Development Goals (SDGs) in Asia and the Pacific that showed that policymakers are aware how the SDGs could help address the region's development unsustainable directions, in both marine and terrestrial ecosystems, and resource-intensive consumption and production. However, there are gaps to make the region's development environmentally sustainable (e.g., weak governance, lack of incentives and finance).

- Integrated approaches, systems thinking, and a circular economy model can help close these gaps by facilitating integration of the environmental dimensions of the SDGs into national policies and plans.

- Combining institutional changes that facilitate this integration with improvements in environmental data collection and management systems will also help close these gaps.

- Only when decision-makers see the interconnections between policy and practice will environmental sustainability become the new normal.

- ADB works across a range of sectors and with national statistics offices, so it is strategically well-positioned to champion the institutional and data management reforms needed to assist developing member countries in achieving the environmental dimensions of the SDGs.

\title{
Leveraging the Sustainable Development Goals to Enhance Environmental Sustainability in Asia and the Pacific
}

\author{
Emma Marsden \\ Senior Environment Specialist
}

\author{
Simon Høiberg Olsen \\ Consultant, ADB
}

Eric Zusman

Consultant, ADB

\section{INTRODUCTION: A SUSTAINABLE ASIA AND THE PACIFIC REQUIRES A HEALTHY ENVIRONMENT}

The high stakes of continuing along a trajectory of resource-intensive development globally were well-recognized when the international community agreed upon the 2030 Agenda on Sustainable Development with the Sustainable Development Goals (SDGs) as their centerpiece. Based on the limited regional data available, progress in implementing the SDGs in Asia and the Pacific (Figure 1) 5 years since the agreement is well behind schedule across almost all 17 goals and 169 targets. In some cases, notably on responsible consumption and production, the region is not even moving in the right direction. This regional picture is informed by available subregional and country-level data, analysis of which shows similar unsustainable development patterns. For reasons ranging from weak governance to a lack of incentives and finance to take action on the environment, the consequence is that many developing member countries (DMCs) in the region are suffering from degraded marine and terrestrial ecosystems and resource-intensive consumption and production patterns. Unless urgent action is taken, this unsustainable development path is likely to compromise the region's prospects for delivering prosperity to its people. Without a significant change in course, it is unlikely that the region will achieve the SDGs by 2030.

The SDGs represented a transformative milestone in that they aim to bring together both the global environment and development agendas. This commitment to the environment was reflected in the inclusion of several SDGs that sought to preserve 
Figure 1: Sustainable Development Goals Progress in Asia and the Pacific, 2019

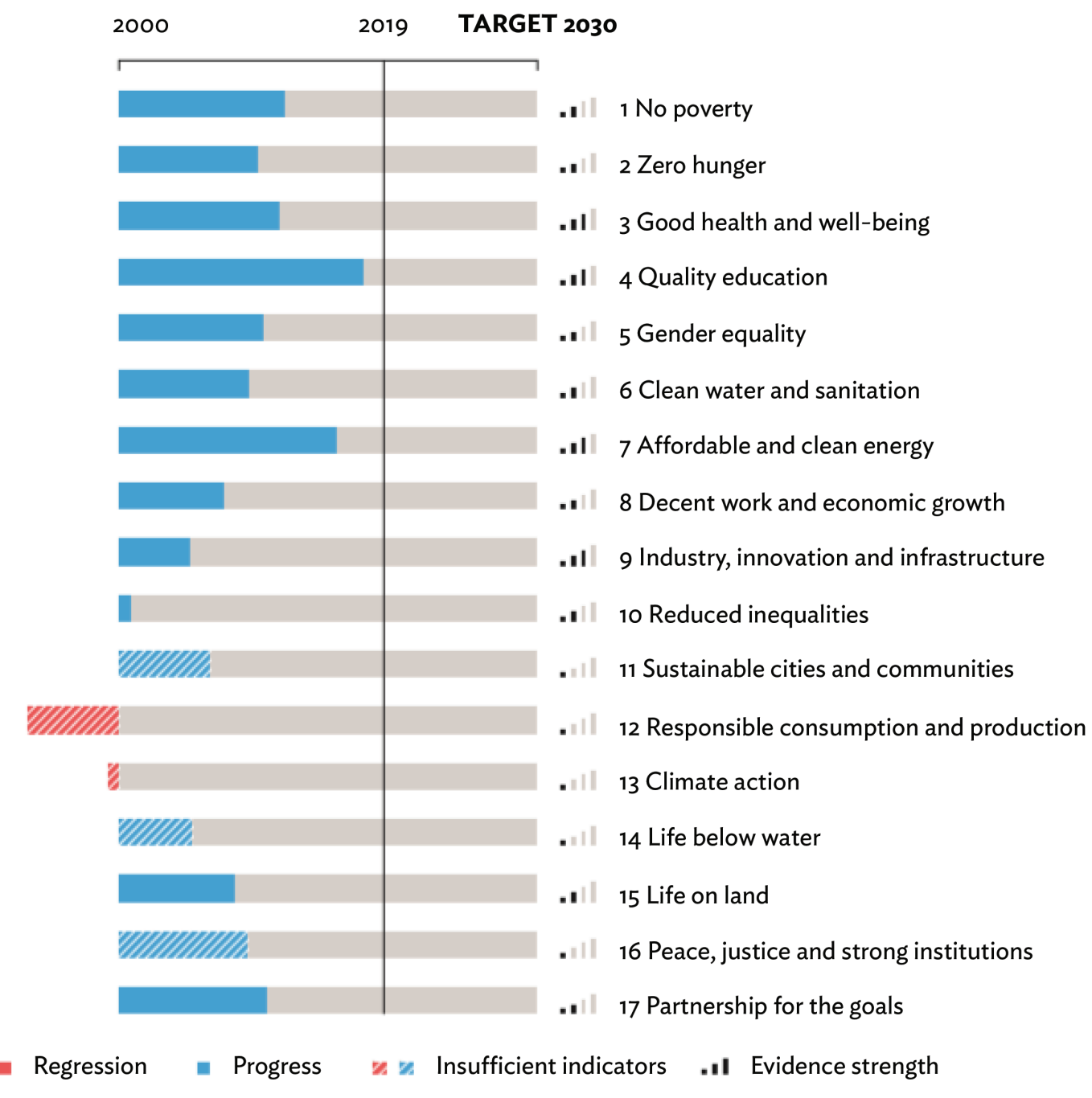

Source: United Nations Economic and Social Commission for Asia and the Pacific. 2020. Asia and the Pacific SDG Progress Report. Bangkok. https://www.unescap.org/sites/default/files/publications/ESCAP_Asia_and_the_Pacific_SDG_Progress_Report_2020.pdf.

marine and terrestrial ecosystems as well as alter unsustainable production and consumption patterns; it was also visible in the agreement to include environmental targets in most other SDGs. A related sign of this commitment were repeated calls to work on not each SDG individually but across the environmental, social, and economic dimensions of the new development agenda holistically. Both the inclusion of these goals and targets and the importance of integration underscored a widely held sentiment among the architects of the SDGs that a failure to protect the environment was a failure to sustain development. ${ }^{2}$

S. Jungcurt. 2016. Towards Integrated Implementation: Tools for Understanding Linkages and Developing Strategies for Policy Coherence. SDG Knowledge Hub. 10 October. https://sdg.iisd.org/commentary/policy-briefs/towards-integrated-implementation-tools-for-understanding-linkages-and-developing-strategiesfor-policy-coherence/.

2 M. Elder. and S. H. Olsen. 2019. The Design of Environmental Priorities in the SDGs. Global Policy. 10 (Supplement 1). pp. 70-82. https://doi.org/10.1111/17585899.12596. 


\section{Table 1: Selected Environment-Related Sustainable Development Goal Targets Addressed by the Technical Assistance Project}
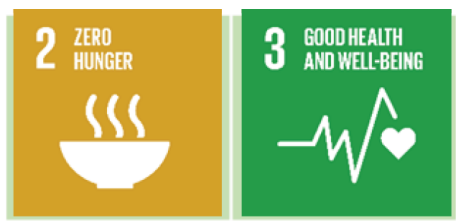

2.4 2.5
3.9

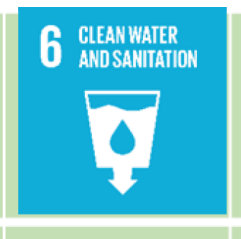

6.3

6.4

6.5

6.6

$6 a$

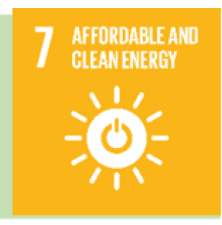

7.2

7.3

$7 b$

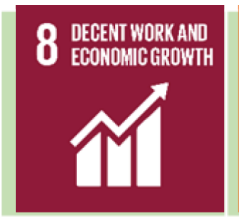

8.4

8.9

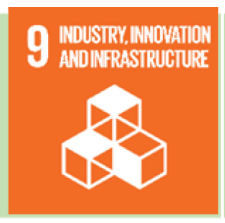

9.4

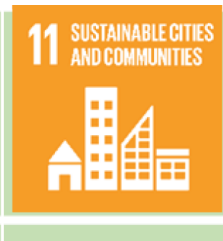

11.4

11.6

11.7

$11 a$

$11 b$

11c

Note: Sustainable Development Goal (SDG) 13 on Climate Action was not covered in the stocktake. This decision was made since other initiatives such as the Paris Agreement were already leading to sufficient financial and other resources flowing to climate change. Furthermore, the risk that countries will neglect SDG 13 is far less than for the other environmental dimensions, although addressing many of the above targets would have considerable benefits for the objectives of SDG 13 as well.

Source: Asian Development Bank. 2019. Strengthening the Environment Dimensions of the Sustainable Development Goals in Asia and the Pacific: Stocktake of National Responses to Sustainable Development Goals 12, 14, and 15. Manila. https://www.adb.org/publications/environmental-dimensions-sdgsnational-responses.

A similar sentiment sat at the core of the approval by the Asian Development Bank (ADB) of a technical assistance project in 2016 entitled Supporting Implementation of EnvironmentRelated Sustainable Development Goals in Asia and the Pacific. ${ }^{3}$ The project grew both from a recognition of the foundational importance of the environment to the region's continued socioeconomic development, as well as a realization that ADB's DMCs may need support to leverage the SDGs to improve their environment. Toward that end, the project was implemented in two phases. The first phase focused on taking stock of how countries in Asia and the Pacific were responding to three environment-related goals (SDG 12, SDG 14 , and SDG 15) plus several other environment-related targets (Table 1) as well as profiling decision-making support tools that could help strengthen that response. ${ }^{4} \mathrm{~A}$ second phase consisted of three interventions that helped selected DMCs (Mongolia, the Philippines, and Viet $\mathrm{Nam}$ ) to fill essential gaps and needs identified from the first phase, in relation to data, policy coherence, and cross-sector planning. ${ }^{5}$ The work done in the three DMCs is further contributing to achieving SDG targets 17.14 (on enhancing policy coherence for sustainable development) and 17.18 (on enhancing capacity building support to developing countries to improve the availability of data), which are critical to delivering the SDGs.

This brief describes the main learnings from the project, breaking them up by the two previously mentioned phases. It also presents recommendations for carrying forward its central objective of making the region's development environmentally sustainable.

3 ADB. 2016. Supporting Implementation of Environment-Related Sustainable Development Goals in Asia and the Pacific. Manila. https://www.adb.org/sites/default/ files/project-document/215401/50158-001-tar.pdf.

4 SDG 12 on Responsible Consumption and Production; SDG 14 on Life Below Water; SDG 15 on Life on Land.

5 DMCs were selected based on expressions of interest received from government officials. 


\section{PHASE 1: WHERE ARE WE NOW?}

Between 2017 and 2018, the first phase of the project began with a stocktake of the performance of 15 DMCs on the environmental dimensions of the SDGs. ${ }^{6}$ This stocktake included interviews with policymakers and other key informants in 14 out of 15 of the DMCs, plus an initial regional workshop to understand both regional and national environmental priorities as well as policies and projects being implemented to help achieve those priorities. ${ }^{7}$ The stocktake report provides further details of this process, including the DMCs involved and questions asked during interviews.

\section{Stocktake Findings}

The stocktake showed that most policymakers were aware of SDGs 12, 14, and 15 and the other environment-related targets. This high level of awareness was partially attributable to existing national policies on issues, such as waste or air quality management, as well as involvement in multilateral environmental agreements and the 10-Year Framework of Programmes on Sustainable Consumption and Production. Yet, while many of the DMCs were working on the environment, they often encountered barriers to taking actions that were consistent with the letter or spirit of the SDGs. Rather than working across goals and targets, most DMCs employed downstream approaches to "conventional" environmental issues. Those working on environmental policy and governance will be familiar with the frequently cited reasons for the lack of more integrated approaches. They include inter-ministry or cross-agency coordination challenges, limited technical and human resources, the high costs of gathering environmental data, and challenges in developing monitoring indicators.

Other findings from the stocktake were more encouraging. For instance, many DMCs were adopting good practices and had accrued useful experiences in the region. Some of these practices include Bhutan's alignment of national key result areas with the SDG indicators; Indonesia's climate change and biodiversity budget tagging work; the Lao People's Democratic Republic's enhancement of enabling policies and regulatory frameworks by capitalizing on the SDGs; the People's Republic of China's mobilization of green finance to catalyze cleaner production; and Sri Lanka's engagement in SDG mapping exercises to strengthen institutional coordination. Disseminating and scaling these practices could help reverse many of the trends identified in the stocktake and recent SDG assessments.

\section{Tools Compendium}

The stocktake suggested that there was an expanding family of decision-making tools that could help DMCs get back on track. A tool compendium was then developed to familiarize policymakers and other stakeholders with 143 tools and methods that could enhance their work on the environmental dimensions of SDGs. ${ }^{8}$ The compendium showed that many of these tools could address specific need areas, such as integrated planning, stakeholder engagement, budgeting, and data management. It further demonstrated that the tools ranged greatly in scope (from issue-specific to context-dependent) as well as required input data (from statistics to qualitative assessments). To help organize the tools, an intuitive scheme was employed that grouped the tools by the SDG(s) they targeted and the stage in the policyimplementation cycle where they are likely to be used. Even with this organizing framework, two points became increasingly clear as project participants began to select tools for practical application: the tools needed to be tailored to particular needs, and coalition-building techniques were required to build support for the technical solutions the tools generated.

\section{PHASE 2: DEVELOPING MEMBER COUNTRY INTERVENTIONS}

From 2018 to 2020, three interventions involving data, policy coherence, and cross-sector planning were developed and implemented in Mongolia, the Philippines, and Viet Nam to carry forward lessons from Phase 1 of the project and improve implementation of the environmental dimensions of the SDGs. ${ }^{9}$ In addition to showcasing the outputs and outcomes of the three interventions, these interventions also helped arrive at recommendations for advancing the project's objectives.

6 ADB. 2019. Strengthening the Environmental Dimensions of the Sustainable Development Goals in Asia and the Pacific: Stocktake of National Responses to Sustainable Development Goals 12, 14, and 15. Manila. https://www.adb.org/publications/environmental-dimensions-sdgs-national-responses; and Development Asia. 2019. Taking Stock of Asia's Response to Environmental Sustainability. 21 October. https://development.asia/summary/taking-stockasias-response-environmental-sustainability.

7 ADB. 2018. Strengthening the Environment Dimensions of the Sustainable Development Goals in Asia and the Pacific: Knowledge-Sharing Workshop Proceedings. Manila. https://www.adb.org/publications/environment-dimensions-sdgs-asia-pacific-proceedings.

8 ADB and United Nations Environment Programme. 2019. Strengthening the Environmental Dimensions of the Sustainable Development Goals in Asia and the Pacific: Tool Compendium. Manila. https://www.adb.org/publications/environmental-dimensions-sdgs-tool-compendium.

9 ADB. 2020. Strengthening the Environment Dimensions of the Sustainable Development Goals in Asia and the Pacific: Knowledge-Sharing Workshop Proceedings. Manila. https://www.adb.org/publications/strengthening-environment-sdgs-asia-pacific; and ADB. 2020. 2nd Regional Knowledge-Sharing Workshop on Strengthening the Environment Dimensions of the Sustainable Development Goals in Asia and the Pacific. Manila. 27-28 November. https://events. development.asia/learning-events/2nd-regional-knowledge-sharing-workshop-strengthening-environment-dimensions-sdgs. 


\section{Mongolia: Policy Coherence and Data Management}

In Mongolia, two related interventions with the National Development Agency (NDA) on policy coherence, ${ }^{10}$ and the Ministry of Environment and Tourism and National Statistics Office on data management were undertaken. ${ }^{11}$ The data management intervention followed on from the successful completion of an ADB technical assistance project on Strengthening Capacity for Environmental and Economic Accounting. ${ }^{12}$

One challenge that had been identified in the stocktake concerned the lack of policy coherence between environmental and socioeconomic policies; attaining both horizontal and vertical coherence is critical for ensuring sustainable development. With over 200 existing national policies, the challenge of achieving coherence across their provisions persists in Mongolia; hence the NDA decided to focus on developing a qualitative matrix-based tool to better integrate the environmental dimensions of the SDGs including SDGs 6, 12 , and 15 into national and sector policies. From the start, it was recognized that the objective was to help all stakeholders improve policy coherence by recognizing the value of nature and the environment. Demonstrating the need to adapt tools to local circumstances, the tool developed in Mongolia drew from Bhutan's Gross National Happiness Policy Screening Tool and a filtration analysis tool that was previously used in developing the Green Development Policy of Mongolia. ${ }^{13}$ The resulting qualitative matrix-based tool can show the impact a policy objective has on 48 environment-related and Mongolia-relevant SDG targets, and whether overall a policy is compatible with these targets or if changes should be made before its adoption. ${ }^{14}$ It showed that existing tools can be combined and made fit-forpurpose in inventive and creative ways. Having an overarching coordinating body such as the NDA that sees the value and necessity of cross-sector coordination was also essential to make this possible.
At the risk of oversimplification, the tool used a matrix with 48 questions based on the previously mentioned SDG targets where a policy is assessed and scored depending on its assumed positive or negative impacts on those targets. The tool is designed to be participatory as the scoring is done based on group consensus. It can also be used by nongovernment stakeholders such as civil society organizations or the private sector in assessing their own policies. Thus, while it is qualitative, its result can help the government legitimize and recognize positive interlinkages and minimize or eliminate trade-offs across policies and sectors.

Good quality environmental data and statistics are critical for monitoring and evaluating progress on the environmental dimensions of the SDGs. They can also serve as a basis for planning decisions. To address this challenge, the Ministry of Environment and Tourism and National Statistics Office worked together on improving their environmental data collection and reporting management system as well as establishing pilot accounts under the System of Environmental-Economic Accounting for water, waste, and emissions to air. ${ }^{15}$ Environmental data collection forms (known as "BOH" forms in Mongolia) reflecting data requirements from the SDG indicators, the Framework for Development Environment Statistics, System of Environmental-Economic Accounting, and multilateral environmental agreements, among others, were developed. ${ }^{16}$ With an improved data reporting flow in place and clear guidance and training for data collectors and managers, the intervention is a starting point for the long-term process of improving Mongolia's environmental data quality and assurance. This intervention demonstrated that data management and institutional coordination go hand in hand. Environmental data management requires a solid institutional foundation, just as the SDG institutional architecture requires good socioeconomic data management to function well.

10 Development Asia. 2020. Developing a Tool to Integrate Environmental Goals into National Sector Policies and Plans. 22 January. https://development.asia/ case-study/developing-tool-integrate-environmental-goals-national-sector-policies-and-plans.

11 Development Asia. 2020. Improving Environmental Data Collection and Reporting in Mongolia. 31 March. https://development.asia/case-study/improvingenvironmental-data-collection-and-reporting-mongolia.

12 ADB. 2016. Technical Assistance Completion Report: Strengthening Capacity for Environmental-Economic Accounting in Mongolia. https://www.adb.org/sites/default/ files/project-documents/49299/49299-001-tcr-en.pdf.

13 GNH Center Bhutan. GNH Screening Tool. http://www.gnhcentrebhutan.org/what-is-gnh/gnh-screening-tool/; and Government of Mongolia, National Development Agency. 2020. Desk Review Of Existing Tools For Integrating Economic, Social, And Environmental Sustainable Development Issues. Ulaanbaatar. http://nda.gov.mn/backend/files/Report\%201.\%20Desk\%20Review\%20of\%20Existing\%20Tools\%20for\%20Integrating\%20Economic,\%20Social\%20and\%20 Environmental\%20Sustainable\%20Development\%20lssues.pdf.

14 Government of Mongolia, National Development Agency. 2020. Tool For Integrating Environment-Related SDGs Into Social And Economic Development Policy Planning In Mongolia. Ulaanbaatar. http://nda.gov.mn/backend/files/Report\%202.\%20Tool\%20for\%20Integrating\%20Environment-Related\%20SDGs\%20 Into\%20Social\%20and\%20Economic\%20Policy\%20Planning\%20in\%20Mongolia.pdf.

15 United Nations et al. 2014. System of Environmental-Economic Accounting 2012-Central Framework. https://unstats.un.org/unsd/envaccounting/seearev/seea_ cf_final_en.pdf.

16 United Nations Statistics Division. 2017. Framework for the Development of Environment Statistics. https://unstats.un.org/unsd/environment/FDES/FDES-2015supporting-tools/FDES.pdf. 


\section{Viet Nam: Data Management and Institutional Coordination}

The Viet Nam intervention, led by the Institute of Strategy and Policy on Natural Resources and Environment, also looked at challenges related to environmental data. ${ }^{17} \mathrm{It}$ also made use of existing tools to develop guidance on improving policy coherence and data management. ${ }^{18}$ The Viet Nam intervention was nonetheless unique in that it revealed that taking an integrated approach depends on institutional realities and that leadership buy-in was critical to achieve integration between ministries with and without "conventional" environmental remits. It also found that the current absence of good quality environmental data makes it easier for sector decision-makers to down play the importance of environmental goals. This is unfortunate when environmental degradation has negative consequences for the achievement of their socioeconomic targets.

Beyond leadership, the Viet Nam intervention showed that policymakers can help overcome environmental data challenges and make convincing policy arguments by becoming more literate in relevant data terminology and precise in articulating their data needs. In order to link data to management decisions, it was recommended that investment considerations should rest more heavily on environmental criteria, in addition to socioeconomic criteria. It was also advised that budget allocations could be shared between ministries so that budgets and implementation responsibilities for environment-related activities are not the sole responsibility of one ministry and/or department-such cross-institutional collaboration could be formalized by revising mandates.

\section{The Philippines: Cross-Sector Planning}

The Philippines focused on creating an action plan for sustainable consumption and production to achieve SDG 12 and support a transition to a circular economy model. ${ }^{19}$ The main motivation for the National Economic and Development Authority to develop the action plan was to strengthen implementation of sustainable consumption and production initiatives, recognizing the need to sustain economic growth without compromising the environment. The action plan is envisaged as a framework to guide sectors and local government to implement policy reforms and a set of actions over the short, medium, and long term. Figure 2 shows the methodology adopted to develop the plan, the important lesson being that the engagement process through which it was formulated was just as critical as the substance of the plan. That engagement process placed an emphasis on participation and co-design, creating multi-stakeholder buy-in across different sectors and actors. ${ }^{20}$ This emphasis, in turn, contributed to institutional development. The Philippine Council for Sustainable Development, originally established in 1992 and comprising government, civil society, business, and labor representatives, was reactivated to serve as a steering and approving body for the action plan. The engagement process also underscored that working on the SDGs is both a technical and political exercise. Yet, some of the nontechnical political challenges - such as vested interests - can be managed by careful coalition building that aligns the interests of key stakeholders within and beyond government.

\section{CONCLUSION AND RECOMMENDATIONS: WHERE DO WE GO FROM HERE?}

The project generated several conclusions suggesting a way forward, which were discussed in the final knowledge-sharing regional workshop. These begin with the main finding from the stocktake that, while the SDGs have helped raise awareness of the foundational importance of the environment, as of now most national policy and planning processes are still failing to reflect the environment's pivotal role. Existing policies and plans, institutional arrangements, and data reporting and management systems tend to treat the environment as an add-on. Gaps between environmental awareness and the actions needed to make the region's development environmentally sustainable persist in Asia and the Pacific, although this need not be the permanent state of

17 Development Asia. 2020. Improving SDG Implementation in Viet Nam. https://development.asia/case-study/improving-sdg-implementation-viet-nam.

18 The SDG Interlinkages Framework tool from M. Nilsson et al. 2016. A Draft Framework for Understanding SDG Interactions. https://council.science/wp-content/ uploads/2017/05/SDG-interactions-working-paper.pdf; the data/priority matrix from M. Bordt and A. Bidarbakht Nia. 2018. SDG Implementation-What to Do When It's Not Clear What to Do? UNESCAPStats Brief. (16). https://www.unescap.org/resources/stats-brief-august-2018-issue-no-16-sdg-implementationwhat-do-when-it-s-not-clear-what-do; the environmental statistics self-assessment tool from United Nations Statistics Division. 2018. Environment Statistics Self-Assessment Tool. https://unstats.un.org/unsd/envstats/fdes/essat.cshtml; and ADB. 2020. Supporting Implementation of Environment-Related Development Goals in Asia and the Pacific: Viet Nam's MONRE Environmental Monitoring and Evaluation Implementation Guidance-Consultants report. https://www.adb.org/ projects/documents/reg-50158-001-tacr-1.

19 Development Asia. 2020. Developing an Action Plan for Sustainable Consumption and Production in the Philippines. https://development.asia/case-study/ developing-action-plan-sustainable-consumption-and-production-philippines; and ADB. 2020. Supporting Implementation of Environment-Related Sustainable Development Goals in Asia and the Pacific: Circular Economy in the Philippines. Consultant's report. Manila (TA 9245-PHI). https://www.adb.org/projects/ documents/phi-50158-001-tacr-0.

20 Stakeholder consultations were conducted at the national and subnational level. The involvement of stakeholders from the subnational level was critical since the local governments will be central to operationalization of the action plan at the local level, helping to ensure the relevant national goals and targets can be achieved. 
Figure 2: Methodology for Development of the Action Plan on Sustainable Consumption and Production

Scoping Phase

\begin{tabular}{|c|c|c|c|c|c|}
\hline $\begin{array}{c}\text { Step 1: } \\
\text { Assessment } \\
\text { of current } \\
\text { SCP and CE } \\
\text { situation in } \\
\text { the } \\
\text { Philippines }\end{array}$ & $\begin{array}{c}\text { Step 2: } \\
\text { Mapping of } \\
\text { SDG } 12 \\
\text { interlinkages; } \\
\text { data and } \\
\text { tools; and } \\
\text { key areas }\end{array}$ & $\begin{array}{c}\text { Step 3: } \\
\text { SDG } 12 \\
\text { stakeholder } \\
\text { mapping }\end{array}$ & $\begin{array}{c}\text { Step 4: } \\
\text { Development } \\
\text { of SCP } \\
\text { framework }\end{array}$ & $\begin{array}{c}\text { Step 5: } \\
\text { Identification } \\
\text { and } \\
\text { prioritization } \\
\text { of key } \\
\text { strategies } \\
\text { and } \\
\text { interventions }\end{array}$ & $\begin{array}{c}\text { Step 6: } \\
\text { Draft SCP } \\
\text { Action Plan } \\
\text { consultations } \\
\text { and policy } \\
\text { development }\end{array}$ \\
\hline $\begin{array}{c}\text { Tools: } \\
\text { Desk review, } \\
\text { expert } \\
\text { interviews }\end{array}$ & $\begin{array}{c}\text { Tools: } \\
\text { IGES } \\
\text { mapping tool, } \\
\text { ICSU } \\
\text { framework, } \\
\text { stakeholder } \\
\text { consultations }\end{array}$ & $\begin{array}{c}\text { Tools: } \\
\text { Four-step } \\
\text { stakeholder } \\
\text { mapping, } \\
\text { influence/ } \\
\text { interest } \\
\text { analysis }\end{array}$ & $\begin{array}{c}\text { Tools: } \\
\text { Participatory } \\
\text { visioning, } \\
\text { backcasting, } \\
\text { theory of } \\
\text { change }\end{array}$ & $\begin{array}{c}\text { Tools: } \\
\text { Prioritization } \\
\text { matrix, } \\
\text { stakeholder } \\
\text { consultations }\end{array}$ & $\begin{array}{l}\text { Tools: } \\
\text { Synthesis of } \\
\text { steps } 1-5 \\
\text { expert } \\
\text { elicitation }\end{array}$ \\
\hline
\end{tabular}

$\mathrm{CE}=$ circular economy, ICSU = International Council for Science, IGES = Institute for Global Environmental Strategies, SCP = sustainable consumption and production, SDG = Sustainable Development Goal.

Source: Asian Development Bank. 2020. Supporting Implementation of Environment-Related Sustainable Development Goals in Asia and the Pacific: Inputs to the Philippine Action Plan for Sustainable Consumption and Production. Consultant's report. Manila (TA 9245-PHI). https://www.adb.org/sites/default/files/projectdocuments/50158/50158-001-tacr-en.pdf.

affairs. The corona virus disease (COVID-19) crisis that emerged as the project was ending has exposed to the mainstream some of the more complex interlinkages between the environmentincluding the illegal wildlife trade, biodiversity loss, and air pollution-and ensuring continued human health, well-being, and socioeconomic development.

The project showed there is great potential to strengthen integration of the environmental dimensions of the SDGs in national policies and plans, for example, by closing the gaps using integrated approaches, systems thinking, and a circular economy model. Interest in these concepts is peaking at the same time governments are reflecting the SDGs in a wide range of policies and plans, thus tools and knowledge that can help policy and decision-makers to meaningfully apply these concepts in diverse contexts will be beneficial. The adoption of existing decision-making tools to enhance policy coherence and support cross-sector planning, such as the tool developed under the project by the NDA specifically to suit the context in Mongolia, can help DMCs to advance environmental objectives. The intervention in the Philippines provides a model for cross-sector planning, demonstrating that action planning on SDG 12 and sustainable consumption and production,

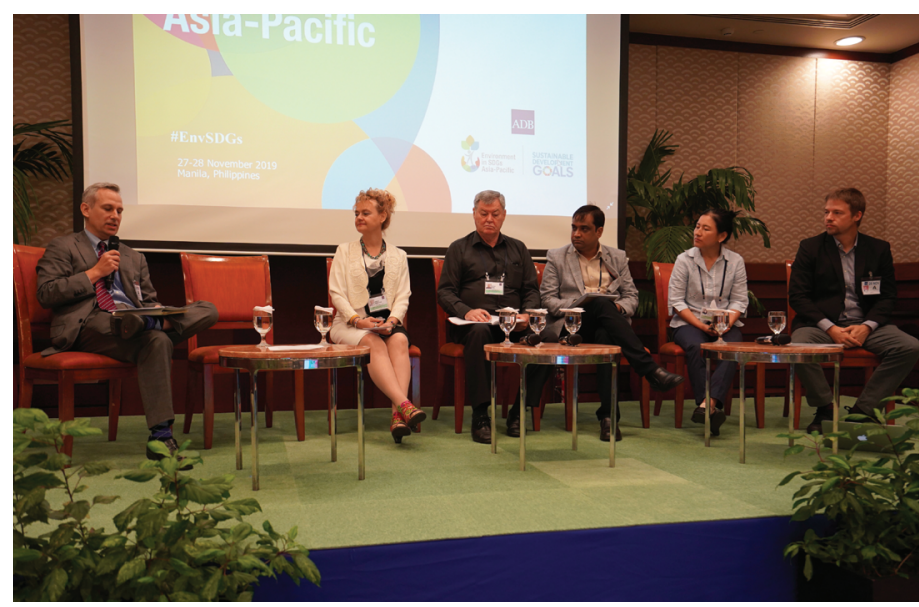

Sharing and exchange of ideas. A snapshot of the panel discussion on the importance of data in context of environment-related Sustainable Development Goals during the final Knowledge-Sharing Regional Workshop in November 2019 (photo by ADB). 


\section{Figure 3: Sustainable Development Goal Interlinkages Mapping} (Adapted from IGES Interlikages Valuation Tool)

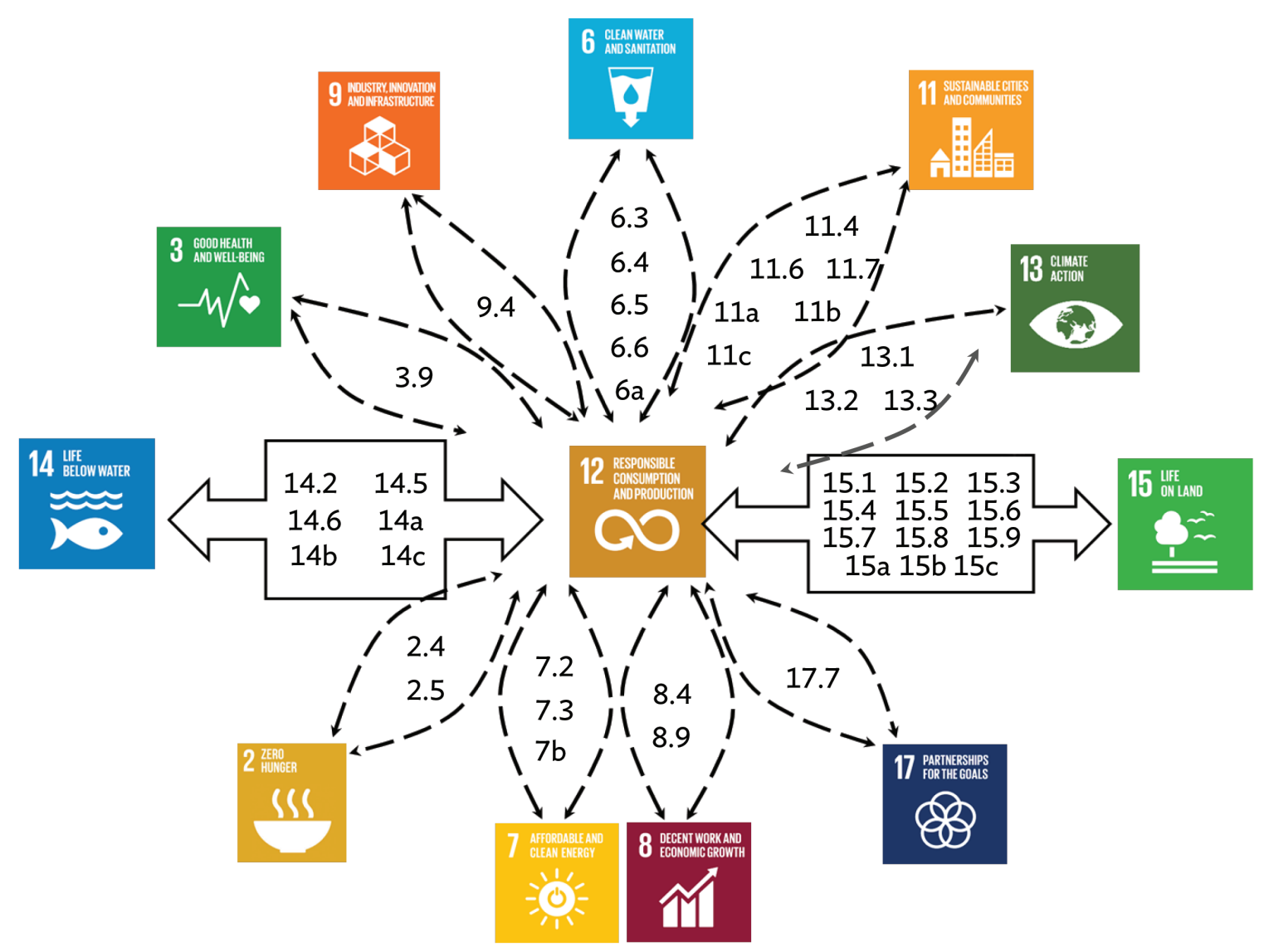

Source: National Economic and Development Authority-Agriculture and Natural Resources. 2019. Philippine Action Plan for Sustainable Consumption and Production. Presentation for the 2nd Regional Knowledge-Sharing Workshop on Strengthening the Environment Dimensions of the SDGs in Asia and the Pacific. Manila. 27 November. https://events.development.asia/node/23036.

which sit at the nexus of many SDGs (Figure 3), can pay both socioeconomic and environmental dividends, offering opportunities for DMCs to engage the private sector and green business, and translate the circular economy model into tangible actions. For governments responding to the COVID-19 crisis by currently reassessing their priorities and preparing stimulus packages and other interventions, these tools will be critical to ensuring that economic recovery does not come at the expense of achieving environmental objectives, and that green approaches to finance, investment, business, and lifestyles are promoted.

Using those concepts as a basis for action will require that governments move away from siloed and segmented decision-making processes. A critical step in this direction will be ensuring environment-related discussions occur in agencies with remits outside the environment, including ministries of planning and finance. Institutional reforms that help decision-makers see and act upon the links between the environment, human health, and well-being exemplify such an important change in this direction. Reforms that can help support long-term transformation in the transport, energy, or water sectors illustrate another sustainable step forward. Combining institutional changes with improvements in data collection and management systems will also factor into the reform process.

ADB could support strengthening of information sharing and exchange, and knowledge building between countries on best practices, policies, and strategies on environmental governance (covering policy coherence and institutional coordination) and environmental data collection and management to address existing data gaps. It can also support DMCs to better integrate environmental considerations into their policies and identify bankable projects that make the link between socioeconomic and environmental objectives. It could also help DMCs make the links between these efforts and broader SDG planning-for 
instance, helping DMCs to highlight the role of the environment in voluntary national reviews and sharing the results at key regional and international meetings such as the Asia Pacific Forum on Sustainable Development and the High Level Political Forum to motivate changes in others. These recommendations could lead to changes in enhancing environmental sustainability in more DMCs than the three targeted in the project.

There are also many things that countries can do. Some practical suggestions include reviewing existing policies for coherence, engaging in cross-sector planning on sustainable consumption and production, adopting integrated approaches to marine or terrestrial ecosystem management, and gradually improving environmental data collection and management systems considering not only environment objectives but also interactions with human health, well-being, and socioeconomic development objectives. For each of these areas, existing decision-making tools can be adapted and made "fit for purpose." National coordination mechanisms can also be established to help sectoral line ministries to engage statistics offices to facilitate communication on data and statistics, and help in stronger, data-based policy making. Further, DMC-led efforts should be undertaken not purely as a technical exercise but with due attention to political realities of adopting green approaches to finance, investment, business, and lifestyles. Carefully designed coalition building could help address political economy challenges such as vested interests, making technically sound planning more politically feasible.

Overall, the project suggests that the Asia and Pacific region is at a crossroads and investment decisions taken now that privilege the environment will have large and lasting positive impacts. The project has highlighted the current lack of integration of environmental considerations at sector level and has facilitated interventions with tools to improve integration. However, it is only when decision-makers at multiple levels see the interconnections between policy and practice that a sustainable future for Asia and the Pacific will be achievable. Only then will environmental sustainability become the new normal.
About the Asian Development Bank

ADB is committed to achieving a prosperous, inclusive, resilient, and sustainable Asia and the Pacific, while sustaining its efforts to eradicate extreme poverty. Established in 1966, it is owned by 68 members -49 from the region. Its main instruments for helping its developing member countries are policy dialogue, loans, equity investments, guarantees, grants, and technical assistance.

ADB Briefs are based on papers or notes prepared by ADB staff and their resource persons. The series is designed to provide concise, nontechnical accounts of policy issues of topical interest, with a view to facilitating informed debate. The Department of Communications administers the series.
The views expressed in this publication are those of the authors and do not necessarily reflect the views and policies of ADB or its Board of Governors or the governments they represent. ADB encourages printing or copying information exclusively for personal and noncommercial use with proper acknowledgment of ADB. Users are restricted from reselling, redistributing, or creating derivative works for commercial purposes without the express, written consent of ADB.

Asian Development Bank

6 ADB Avenue, Mandaluyong City

1550 Metro Manila, Philippines

Tel +63286324444

Fax +63286362444

www.adb.org/publications/series/adb-briefs 